\title{
World's first successful penis transplant at Tygerberg Hospital
}

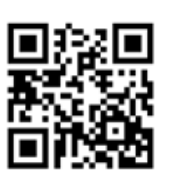

A multidisciplinary team at Tygerberg Hospital has performed the first-ever successful penile transplant, giving hope to victims of

botched ritual circumcisions and penile cancer and even men with severe erectile dysfunction.

The grateful and delighted 21-year-old recipient, one of 250 known formerly hopeless penile amputees across the country annually, has been out of hospital for over a month and reports full sexual and urinary function. Nine more candidates are being psychologically and medically prepared for transplantation as part of the globally ground-breaking pilot study. All are victims of failed ritual circumcision - most from the Eastern Cape, with several reported to have contemplated suicide, so powerful is the cultural stigma. The intervention is particularly apt in South Africa (SA), where

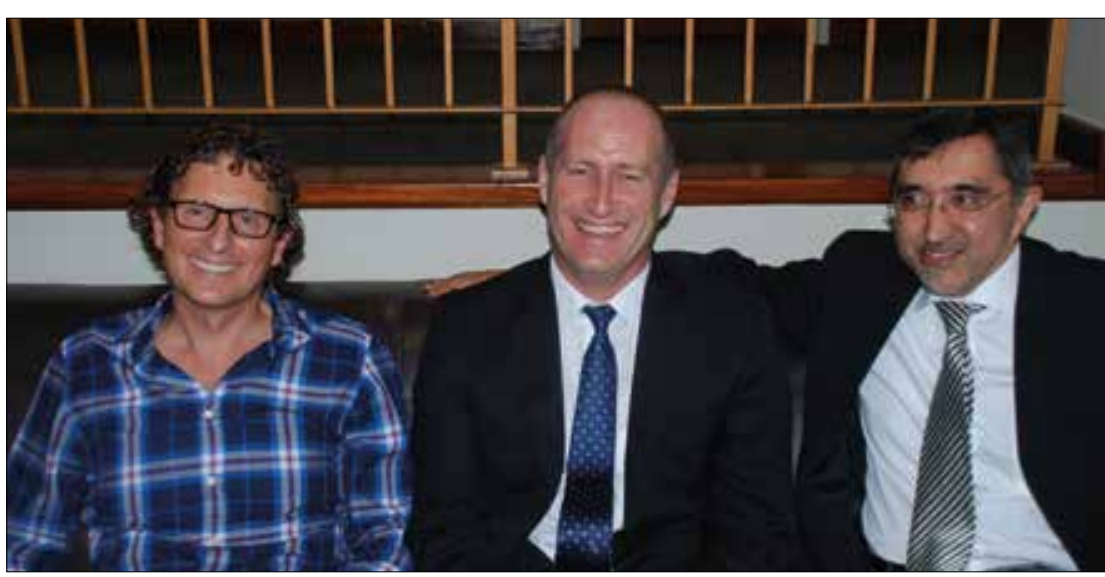

Transplant team $(l-r)$ plastic surgeon Prof. Frank Graewe, urologist Prof. André van der Merwe and immunologist Prof. Rafique Moosa. Photo: Chris Bateman.

the prevalence of penile loss is way above the international average, especially in the Xhosa-speaking region of the Eastern Cape. One snapshot of the only available hospital admissions data for life-threatening postritual-circumcision complications in that province stood at 200 patients in December 2001 alone, with 11 mutilations. 


\section{Diligent, careful groundwork}

The success is the culmination of 4 years of clinical and ethical preparation, intensive laboratory work on cadavers, frustration in finding willing donors, and careful groundwork to ensure that the procedure and its concomitant lifelong immunesuppressant treatment are replicable and affordable to all.

Dr Dimitri Erasmus, Chief Executive of Tygerberg Hospital, emphasised that the procedure was not an answer to the ongoing loss of life and reproductive organs caused by inexpert ritual male circumcision - a uniquely SA phenomenon. 'While hugely significant, this is a life-changing, not a lifesaving procedure. The focus should remain on preventive efforts,' he said. The 9-hour operation was conducted on 11 December last year by a team led by Prof. André van der Merwe, head of Stellenbosch University (SU)'s Division of Urology, with his university counterpart in plastic surgery, Prof. Frank Graewe, and SU's Department of Medicine chief and transplant immunologist, Prof. Rafique Moosa, in attendance. The penis, along with the heart, lungs, kidneys, liver, skin and corneas of an unidentified donor, was removed in a lengthy procedure where each team had to wait their turn to harvest an organ. Van der Merwe said that one of the major obstacles encountered on the long road to success was the reluctance of donor families to bury their loved ones without a penis. By building a look-alike organ using flaps from the forearm, they overcame this and expect a smoother path to donor willingness in future. Asked how they knew their patient had achieved full sexual competence, Graewe said he had recently sent them an identifiable cell-phone picture of an erection, while tumescence had been observed when he was returned to the operating table 4 days after the operation to remove a clot in one of the penile arteries. The penile stump had also been 'very active' under anaesthetic.
His recovery included a second return to theatre for drainage of a haematoma and to repair a small fistula of the urethra but the team has exceeded their greatest expectation, which was that the young man be fully functional at 2 years. Instead this happened at 3 and a half months.

Tygerberg Hospital has a distinguished record in its partnership with SU's Faculty of Medicine and Health Sciences. This includes SA's first in vitro fertilisation procedure, resulting in the birth of the country's first test-tube baby, an innovative microsurgical heart valve, and multiple microsurgical reconstructions after surgery for breast, head and neck cancers.

\section{Van der Merwe said that one of} the major obstacles encountered on the long road to success was the reluctance of donor families to bury their loved ones without a penis. By building a lookalike organ using flaps from the forearm, they overcame this and expect a smoother path to donor willingness in future.

\section{Historical precedent unsuccessful}

A similar penile transplant procedure was performed in Guangzhou General Hospital in China in 2006, involving a 44-year-old recipient who had lost his penis in an accident, but surgeons had to remove the organ 2 weeks after the operation when skin problems resulted in an aesthetic problem. Graewe said the Chinese used a 'completely different approach', warming the donor penis up with an infrared lamp postoperatively, which increased the metabolic requirements, instead of increasing the blood supply as they had. 'But I think the crucial difference appears to have been inadequate psychological workup' he stressed, adding that the recipient's girlfriend had strongly objected to the result. The SA team, which included Dr Nicola Barsdorf, Head of Health Research Ethics at SU, said that because the recipient's blood vessels that would have matched those of the donor were 'obliterated' by the ritual circumcision modus operandi, with excessive fibrosis having occurred, they could only use the local nerve structure. This meant that they had to reroute a blood vessel from the patient's lower abdomen to the perineum, where they connected it to the new penis. The surgeons also connected three blood vessels, each between $1 \mathrm{~mm}$ and $2 \mathrm{~mm}$ in diameter, to ensure sufficient blood flow to the transplanted organ, two dorsal nerves of the same diameter to restore sensation, the urethra, enabling the recipient to urinate through the penis, and the corpus cavernosum, which allowed him to obtain an erection.

Barsdorf said that the research team had addressed the issue of therapeutic misconception (i.e. the risk that a research participant may not fully understand the experimental nature of the treatment) impeccably. The patient had been counselled repeatedly over an extended period about the potential risks and benefits. The transplant team's partnership with local public health structures also meant that the procedure would be delivered to the people who needed it most by being on offer in state facilities to vulnerable groups that are often unable to afford or access state-of-theart healthcare.

Graewe said the patient has reported that he is enjoying sex 'at least once a week', rendering the transplant team somewhat anxious. Van der Merwe revealed that the transplanted organ was not circumcised. 'We've encouraged him to come straight to us for that', he added with a smile.

\section{Chris Bateman}

chrisb@hmpg.co.za

S Afr Med J 2015;105(3):251-252.

DOI:10.7196/SAMJ.9602 